This item was submitted to Loughborough's Institutional Repository (https://dspace.lboro.ac.uk/) by the author and is made available under the following Creative Commons Licence conditions.

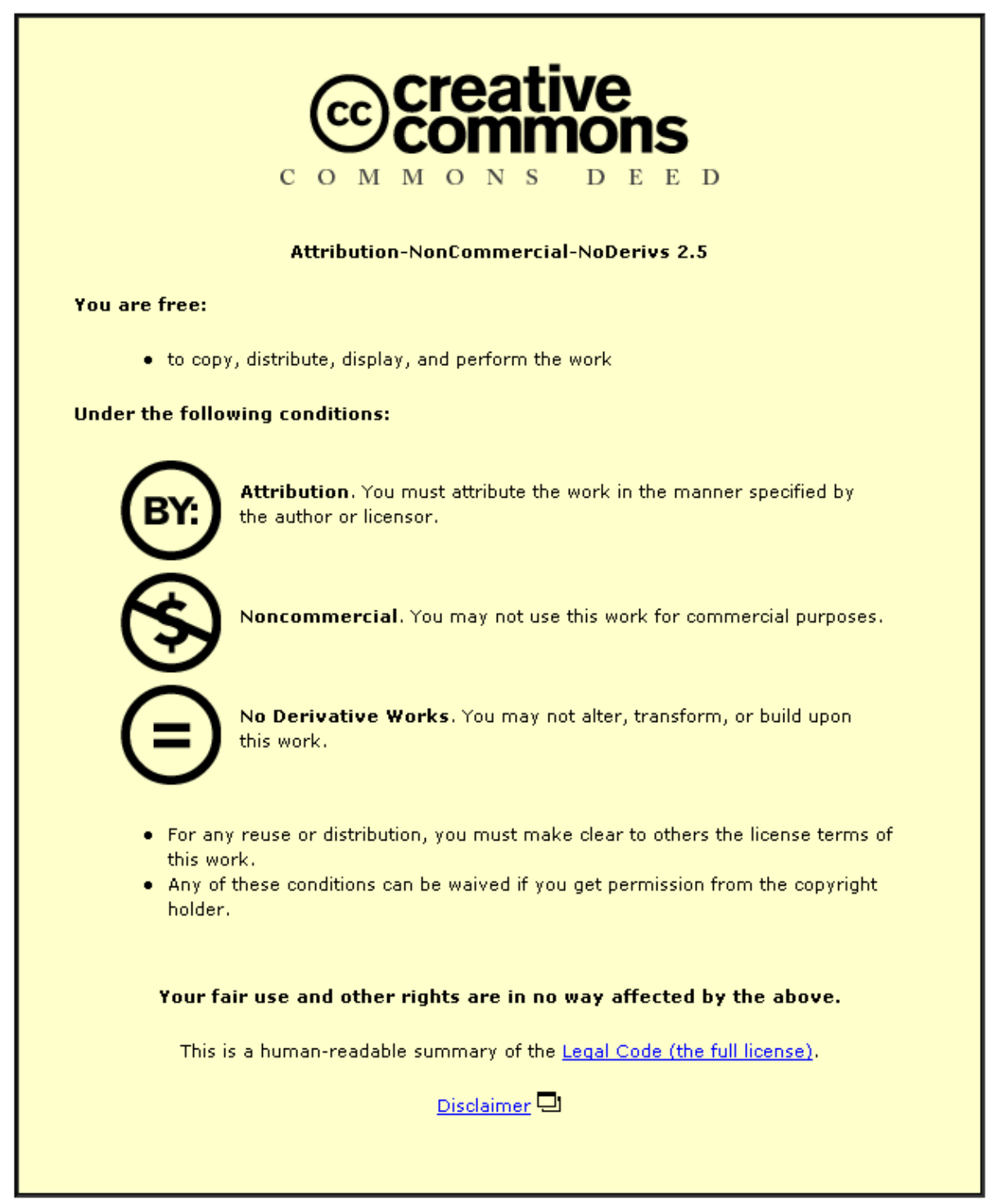

For the full text of this licence, please go to: http://creativecommons.org/licenses/by-nc-nd/2.5/ 


\title{
Electrochromic Glazing and Facade Photovoltaic Panels: A Strategic Assessment of the Potential Energy Benefits
}

\author{
J. Mardaljevic $\nmid$ and A. Nabil* \\ Institute of Energy and Sustainable Development \\ De Montfort University \\ The Gateway, Leicester, LE1 9BH, UK \\ $\dagger$ Corresponding author jm@dmu.ac.uk \\ Phone: +44 (0) 1162577972 \\ Fax: +44 (0) 1162577981
}

\begin{abstract}
This paper describes a methodology to compare the energy benefit that may result from the adoption of two very different facade technologies in non-domestic buildings. A comparison is made of the energy benefit that might result from: (a) replacing conventional glass with electrochromic glazing; and, (b) installing PV panels across the opaque sections of vertical facade. The energy benefit from electrochromic glazing is predicted on the basis of displaced electric lighting usage against standard glazing with blinds, whereas the energy benefit from facade PV panels is equal to their delivered electrical output. The evaluation setting is a 'typical' six metre deep perimeter office space with vertical glazing. Office orientations for each of the four cardinal compass points are considered. Performance evaluations are founded on a full year's hourly meteorological data for fourteen locales across the world. The predicted energy benefit from electrochromic glazing and facade PV are related to the total annual vertical irradiation incident on
\end{abstract}

${ }^{*}$ Now at BRE, Garston, Watford WD25 9XX, UK 
the building facade. The findings indicate that the energy benefit that results from replacing standard glazing with electrochromic glazing may exceed that of facade PV for the majority of cases studied. Surprisingly, electrochromic glazings are found to provide the greatest energy benefit for those cases at the lower end of the experienced range in total annual vertical irradiation. The effectiveness of widespread deployment across multiple facades for each locale is examined. The likelihood that electrochromic glazing alone can offer sufficient solar protection without recourse to additional shading is assessed using the recently formulated useful daylight illuminance scheme.

Keywords: Photovoltaic, Electrochromic glazing, Daylight, Simulation.

\section{Introduction}

Non-domestic buildings in cities are a major consumer of energy. Of the mature technologies that have been recently deployed to reduce the primary energy consumption of buildings, the in-situ generation of electricity by photovoltaics (PVs) is considered one of the most promising ${ }^{(1)}$. A recent report by the UK Department of Trade and Industry gives details of 16 typical building integrated photovoltaic (BIPV) projects $^{(2)}$. For these demonstration projects - recently completed, planned or speculative - open sites with

minimal nearby obstructions were the norm. In the medium-to-long-term however, BIPV for typical office buildings will need to be considered since this is where the majority of the energy use takes place.

In addition to offsetting primary energy demand, it is recognised that there is significant potential to reduce the electrical consumption in offices through the effective use of daylight ${ }^{(3)}$. At present, however the use of daylight in office buildings is considered a greatly under-exploited resource. In large part this is because the highly variable nature of daylight illumination often produces extremes of over-provision of illuminance that are difficult to 
temper to moderate levels using conventional methods. For example, when blinds are lowered in response to high levels of illuminance and/or glare, there is usually little attempt to tune to the slat angle to achieve some optimum between shading efficacy and daylight provision. The lowering of blinds when illuminances are perceived to be excessive is often accompanied by the switching on of electric lights (if they are not on already).

In contrast to the 'shutter mode' of operation for standard blinds, a glazing with a transmissivity that varies continuously between clear and dark extremes would offer a much greater degree of control over the luminous environment. Indeed, the dynamic control of daylight has been termed the "Holy Grail of the fenestration industry" (4). In principle, the approach is simple: the transmission properties of the glazing are varied to achieve the best possible luminous environment. Formulations based on electrochromic (EC) principles, where the glazing transmission is modulated by a small applied voltage, are considered the most promising at present. In practice, the formulation and production of commercial-sized EC glazing has proved a formidable task. Recently however, a number of technical hurdles have been overcome, and pre-production samples of EC glazing have been deployed in test facilities for evaluation ${ }^{(5)}$.

The most recognizable distinguishing feature of the elements that comprise the facade of modern office buildings is that they are either transparent or opaque. The hypothetical settings for the 'advanced facade' performance evaluation described below are:

- Where the opaque section of building facade is comprised of PV panels.

- Where EC glazing is used in place of standard glazing.

The energy benefit of the PV panels is assessed in terms of their annual power output. Whereas the energy benefit of EC glazing is based on their 
capacity to reduce the annual electric lighting consumption - against standard glazing and blinds - by providing a controlled daylit environment. ECs and PVs each have their own proponents, and both technologies have the potential to substantially reduce carbon emissions from non-domestic buildings through wide-scale deployment. Additionally, both technologies are likely to incur considerable capital costs over standard construction practices. Thus, for practical deployment with limited budgets (as opposed to demonstration projects), ECs and facade PVs can be considered to be competing technologies since it is likely that one would have to be chosen over the other. This paper aims to address the following questions:

1. What is the energy benefit - measured against current practice - that might reasonably be expected from each of the technologies?

2. What is the relation between the predicted energy benefit and the prevailing local climate and facade orientation?

3. How effective is the technology when deployed across more than one facade of the building?

The power generated by a PV panel will, of course, depend strongly on the magnitude of the incident irradiation. The relation between useful (i.e. potentially energy saving) levels of daylight illuminance and prevailing climate is less straightforward ${ }^{(6)}$. In order to elucidate these relations, and for the findings to have widespread, global applicability, the evaluation was carried out for all 56 combinations of four office orientations and fourteen climate datasets from around the world. In contrast to an earlier study carried out by Vartiainen, where the combined electricity benefits of daylighting and PV were assessed for varying proportions of glazing and PV panels ${ }^{(7)}$, this study used a fixed proportion which is more typical of that commonly found in modern high rise office buildings. 
The Basecase setting provides the datum against which the energy benefit of both EC glazing and facade PV was determined. For this study, the Basecase is a typical perimeter office with clear double glazing, venetian blinds and luminaires with on/off switching to provide 500 lux. For the advanced glazing case, the standard glazing was replaced with electrochromic glazing, and the on/off switching was replaced with daylight responsive dimming controls that provided top-up artificial lighting to 500 lux. For the PV case, the opaque section of vertical facade below the window was modelled as a high-efficiency BIPV array.

The energy benefit for the EC glazing case was calculated solely on the basis of daylight displacing the use of electric lighting. This depends in large part on the operational models for: the blinds, the light switching, and the EC glazing. A deterministic model of occupant behaviour was used for the Basecase. This is acknowledged to be a simplification and the consequences of its use are discussed in Section 4. The key operational factor for the EC glazing (the ratio of maximum to minimum visible transmittance) was founded on values likely to be achieved for production samples in the near future. The consequence for the energy benefit predictions resulting from plausible deviations from the Basecase model is discussed in the Results section.

In order to allow for comparative assessment of EC glazing against facade photovoltaics (FPVs), the energy benefits were evaluated on a basis that is common to both, i.e. per metre width of facade. The rationale for this is discussed in the next section. The predicted energy benefits from all the combinations of glazing orientation and climate are related to the experienced vertical total annual irradiation (VTAI). The VTAI is a measure of the long term exposure of the facade (and glazing) to radiation from the sun and the sky. VTAI therefore is a parameter that is specific to both the facade 
(and glazing) orientation and the local climate, and thus may be considered a measure of the local solar micro-climate.

\section{The office models}

\subsection{The Basecase model}

The Basecase building model was a typical side-lit office space with clear glazing. The office had the dimensions shown in Figure 1a and was 3m wide. The reflectivities of the walls, ceiling, and floor were set to be $0.7,0.8$, and 0.2 , respectively. The window had standard $6 \mathrm{~mm}$ clear double glazing with transmittance of 0.76 . The calculation points lay on the workplane $(0.75 \mathrm{~m}$ from the floor), along a straight line from the window to the back of the office. The distance between the window wall and the first point and that between the last point and the back wall was $0.25 \mathrm{~m}$. The spacing between consecutive points was $0.5 \mathrm{~m}$. Hourly-varying internal illuminances were predicted for each of these 12 points using the rigorously validated daylight coefficient (DC) $\operatorname{approach}^{(8)}$.

The operation of blinds for the Basecase office was founded on a deterministic behavioural model where daylight illuminances in excess of a trigger value result in the blinds 'closing'. As this model was devised to mimic the manual operation of blinds, it was considered that discomfort experienced at any point along the length of the office could prompt the occupant at that point to operate the blinds. The operation is termed 'ideal' because it was modelled as perfectly daylight-linked, i.e. the blinds were always shut in response to illuminances greater than trigger value and always retracted whenever the trigger value would not be achieved. In actuality, this deterministic control model cannot be said to offer high levels of realism since there is no human factors component to the operation to account for vari- 
able occupant response to daylight changes. Its purpose here however is to provide a benchmark for comparison. The trigger value was set to 2000 lux of daylight illuminance. This value was based on a survey of behavioural studies which recorded occupants preference and reaction to daylight illuminance levels. Overall, many occupants appear to prefer or tolerate daylight illuminances higher than the typical 500 lux design value. Above 2000 lux it is reported that the majority of occupants will begin to lower blinds, shades etc. An upper limit for comfortable (or at least tolerable) illuminance of 2000 lux was also used by the authors in the formulation of a new daylight design paradigm called useful daylight illuminance (UDI) ${ }^{(6)}$.

Measurements in office spaces have found that approximately $20 \%$ of incident daylight penetrates venetian blinds when they are fully drawn and the slat angle is $\approx 60^{\circ}$, which is considered 'closed' ${ }^{\prime}(9)$. Simulation tests were carried out modelling in detail a venetian blinds system installed on the window of the office model shown in Figure 1a. The investigation showed that, after removing the direct sun component (if present), the total of the remaining daylight components penetrating fully-drawn venetian blinds was indeed very close to $20 \%$ of that which would arrive inside the office if there were no blinds. Therefore, it was decided that fully drawn venetian blinds would be be modelled as a filter that first removed any existing direct sun component from the transmitted daylight, and then reduced the magnitude of the remaining daylight components (i.e., direct sky, indirect sky, and indirect sun) to $20 \%$ of their original value. The illuminances for unshaded glazing were re-used with the filter applied to mimic the effect of drawn blinds ${ }^{(10)}$.

The Basecase office was taken to be illuminated by three luminaires located at $1 \mathrm{~m}, 3 \mathrm{~m}$ and $5 \mathrm{~m}$ from the window, to cover, respectively, the front, middle, and back zones of the office. The lighting control model used for the Basecase was ideal daylight-linked on/off switching. The luminaire was 
taken to be on whenever the daylight illuminance at the control point for that zone was below 500 lux, and off whenever it was above 500 lux. A value of $80 \mathrm{~lm} / \mathrm{W}$ for the luminous efficacy of the electric lamps was used. The light output ratio of the luminaires (i.e. their efficiency) was taken to be 0.5. Each of the luminaires was considered to be controlled independently of the others according to the lighting requirement and the daylight illuminance of the office zone it illuminated. In addition, if we assume a light loss factor of $10 \%$ due to dirt and ageing depreciation, the average net luminous efficacy of the electric lighting system at workplane level was taken to be $36 \mathrm{~lm} / \mathrm{W}$ for on/off switching. In reality of course, it is unlikely that occupants would respond 'ideally' to varying daylight conditions, and it is more than likely that blinds would be lowered - and the lights left on - more frequently than that predicted here. The likely consequence of this on the findings is discussed later.

The annual electric energy required to provide artificial lighting using the combined blinds and luminaire control strategy was predicted for all 56 combinations of glazing orientation and climate.

\section{$2.2 \quad$ Facade photovoltaic model}

The floor to ceiling height of the office space was $2.7 \mathrm{~m}$. This is a typical value for modern office buildings where the overall floor pitch is around $3.7 \mathrm{~m}$. The height of opaque facade beneath each office sill therefore was $1.75 \mathrm{~m}$, Figure 1b. We assume that $0.25 \mathrm{~m}$ of this height to be used for framing and supporting structure. Thus the height for the PV array was $1.5 \mathrm{~m}$. The annual power output from a PV array $1.5 \mathrm{~m}$ by $3 \mathrm{~m}$ (the width of the office space) was modelled using time-varying irradiances derived from the same DC scheme used for the internal illuminances. The PV array was maximum power point tracked, i.e., the voltage of the array was continuously 
adjusted such that the power produced was a maximum, and that it was gridconnected through a DC-to-AC inverter. Since only a part of a generalised PV array (for the whole facade) was modelled, proper sizing of the inverter (or several string inverters) was not appropriate. Hence, for the DC-to-AC conversion of the electric output in this model, total losses in the balance of the system were taken to be $15 \%$, which is a typical value ${ }^{(11)}$. This was to include inverter losses as well as wiring and mismatch losses. It was also assumed that the PV array was passively cooled, i.e., the heat sink for the thermal energy precipitated in the array was the ambient environment.

The hourly electric output of the PV array was calculated for all daylight hours in the year for all combinations of the four cardinal facade orientations and fourteen climate datasets. In each case, the following procedure was followed:

1. The hourly irradiation incident on the array was predicted using the daylight coefficient method and the site meteorological data.

2. The PV module temperature for every daylight hour was predicted using the thermal model presented by Duffie et al. ${ }^{(12)}$. The model inputs were the ambient temperature; module specifications and the predicted incident irradiation on the module.

3. The electrical output of the PV was determined based on the operating characteristics of a widely-used high-efficiency PV module (the BP585 product) ${ }^{(13)}$

A record of the hourly incident vertical illuminance was also kept. The sum of this quantity gave the the vertical total annual irradiation (VTAI). 


\subsection{Electrochromic glazing model}

The optical properties of EC windows can be modulated using control variables such as incident or transmitted solar radiation, daylight illuminance, ambient air temperature, or space thermal load ${ }^{(14)}$. Previous investigations of control strategies concluded that daylight control of EC switching provided the best overall energy performance, attributed to the large reduction in the required electric lighting energy due to daylighting ${ }^{(15)(16)}$. Thus daylight illuminance was used as the control variable for this study. The earlier studies used the relatively simple daylight modelling algorithms incorporated into thermal models rather than detailed lighting simulation. Also, the optical properties of the EC glazing were modulated between clear and dark states to maintain a daylight illuminance of 500 lux at a reference point located along the centre line of a side-lit office, at workplane level and at a distance equal to two thirds the depth of the office ${ }^{(16)(17)(18)}$. This location for the reference point may far from ideal since maintaining that level of illuminance at the back of a side-lit office can subject the front to potentially uncomfortable high illuminances ${ }^{(6)}$. Instead, the control strategy for this study was designed to maintain a maximum daylight illuminance of 2000 lux, whenever possible, at a reference point much closer to the front of the office, i.e. only $1.25 \mathrm{~m}$ from the glazing. Thus the preferred upper limit for illuminance in the EC model is set to be the same as that which triggers the lowering of blinds in the Basecase office.

The EC glazing was modelled as having a range of visible transmittance that was continuous between 0.1 to 0.8 since these values are believed to represent the limits of achievable performance for production samples in the near future ${ }^{(19)(18)}$. Note that this range is markedly greater than Pilkington EControl (0.15 to 0.5), however more recent production samples from Sage Glass and Asahi are approaching the hypothesised limit of performance ${ }^{(20)}$. 
For the simulation, illuminances derived from daylight coefficients were modulated to mimic the effect of the variable transmittance EC glazing. Whilst this does not give an exact representation of the EC glazing properties in the simulation, tests revealed that deviations are likely to be of the order of $10 \%$ or less. With a ratio of 1:8 for the visible transmittance, 16000 lux is the maximum illuminance (received when in the clear state) that can be reduced to the preferred limit of 2000 lux. The control strategy was as follows:

$$
\begin{aligned}
& \text { If }\left(E_{i} \leq 2000 \text { lux }\right) \quad \text { Then }\left(E C_{\text {trans }}=0.8\right) \\
& \text { If }\left(2000 \text { lux }<E_{i}<16000 \text { lux }\right) \quad \text { Then }\left(E C_{\text {trans }}=\frac{2000 \times 0.8}{E_{i}}\right) \\
& \text { If }\left(E_{i} \geq 16000 \text { lux }\right) \quad \text { Then }\left(E C_{\text {trans }}=0.1\right)
\end{aligned}
$$

Where $E C_{\text {trans }}$ is the instantaneous values of the transmission of the EC glazing and $E_{i}$ is the instantaneous value of the illuminance (predicted for $\left.E C_{\text {trans }}=0.8\right)$. The electric lighting model used for the EC glazing setting was similar to that for the Basecase, only now dimming was incorporated so that artificial illuminance would supplement whatever daylight there was to provide a total of 500 lux. Dimming is expected to incur a further $10 \%$ reduction in the net luminous efficacy due to control gear losses. Thus the net luminous efficacy for the luminaires with dimming was $33 \mathrm{~lm} / \mathrm{W}$. The annual electric energy required to provide artificial lighting using the combined EC and luminaire control strategy with dimming was predicted for all 56 combinations of window orientation and climate.

\subsection{Summary of the office models}

The rationale behind the formulation of the various settings is discussed in this section. The Basecase represents a typical example of current practice: an office with standard glazing, venetian blinds for shading and luminaires 
with on/off switching. Clear glazing is used for all climates and orientations. Whilst this is likely to be an unrealistic option for the sunnier climate zones, an earlier study using the same set of multiple climate zones revealed that clear glazing with blinds gave, in the main, lower annual electric energy demand for lighting than medium or dark tint glazing ${ }^{(6)}$. The Basecase setting has ordinary glazing and a simple on/off control for the electric lighting since this is typical of current practice.

For the EC setting, the simple on/off lighting control of the Basecase is replaced with (individual) daylight responsive controls that use dimming to top-up whatever daylight illuminance is available to 500 lux. Daylight responsive lighting controls must be considered an integral part of any EC system if the potential energy benefits are to be realised ${ }^{(5)}$.

The fourteen climate locales used in the evaluation are listed in Table 1. A simulation flowchart of the daylight coefficient based scheme to analyse a (fixed) building design given an arbitrary orientation and exposed to multiple climates is given in Figure 2. Note that the computation of the daylight coefficient matrices (DCMs) is the most taxing part. Thereafter, the derivation of external irradiances, internal illuminances, electric lighting etc. is fairly swift - almost interactive. For this study, all the time-varying illuminances and irradiances for the various settings, climates and orientations (in excess of five million) were derived from a single set of DCMs. It should now be evident that this paper presents the distillation of a substantial simulation and data-reduction effort, albeit one that was highly optimised and automated. The algorithms, computational techniques and validation of the simulation engine are described in $\mathrm{PhD}$ theses by the authors ${ }^{(8)}(10)$. 


\subsection{Comparing ECs and facade PVs}

To make meaningful comparison between the ECs and facade PVs it is necessary to define a metric that is common to both and which is a key determinant of the potential energy benefit from each of the technologies. The energy benefit from PV is, of course, strongly related to the (facade) area available for the deployment of PV arrays. The energy benefit from ECs defined here as the reduction in electric lighting use against the Basecase cannot be related so easily to the dimensions of the facade (i.e. the glazed area). The EC energy benefit depends on the ability of the EC glazing to effectively modulate the daylight illuminances in the office. Thus, any absolute value for energy benefit will depend of the dimensions of the office space - depth, width and height - and also the reflectivities of the internal surfaces. Reasonable values, typical for many offices, can be assumed for the reflectivity of internal surfaces. Similarly, for typical office spaces the variation in floor to ceiling height across building designs is not that great (the same is also true for the floor spacing). The critical dimension in the assessment of the energy benefit from ECs is the depth of the office space. Evidently, if the office space were very shallow, say only $3 \mathrm{~m}$ deep, then the area of workplane over which daylight could act to displace electric lighting would be small. Thus the predicted energy benefit of EC glazing would also be small. It is important therefore that the office depth should be sufficient to fully realise the potential energy savings of daylight utilisation. A depth of $6 \mathrm{~m}$ presents a reasonable upper limit for the penetration of useful daylight illuminance into a side-lit office space ${ }^{(6)}$.

For a given floor spacing and glazing height, the area of facade, and hence the energy benefit from facade PVs is directly proportional to the width of the facade. For a given depth of office space, the energy benefit that results from replacing standard glazing and blinds with ECs is proportional to the 
area of office space that is illuminated by artificial lights, which in turn is directly proportional to the width along the facade. Thus, the energy benefit from both ECs and facade PVs was determined and compared on a per unit width of facade basis. With this scheme, once the costs of commercial EC products (with the same or similar characteristics to those modelled here) are established, it will be possible to estimate lifetime energy benefits and so determine 'payback' periods on the basis of performance against cost of materials, installation etc. The methodology described here therefore could serve as a basis to decide which of the two technologies offers the greatest energy benefit for a particular combination of locale and glazing orientation.

\section{Results}

\subsection{Annual electric lighting energy usage}

The annual electrical energy for lighting the office was predicted for all 56 combinations of climate and orientation for these two settings:

- Clear glazing, on/off ideal light switching and ideal daylight-responsive blinds drawn when the daylight illuminance exceeds 2000 lux (Basecase setting).

- EC glazing response set to maintain (but not exceed) 2000 lux at the control point and daylight responsive dimming controls (EC setting).

The annual values were normalised to give the annual electrical energy lighting requirement on a per metre width of facade basis (i.e. units of $\mathrm{kWh} / \mathrm{m} / \mathrm{yr}$ ). The results for the Basecase control model are presented in Figure 3. Here, the annual electric lighting energy per metre width of facade $\left(Q_{B}\right)$ is plotted against the vertical total annual irradiation (VTAI). The window orientation is indicated by the compass orientation of the arrow-head symbol (and 
also by colour). The annual electric lighting consumption shows a decreasing trend with increasing VTAI. A least squares linear fit is shown although it is evident that there is a flattening of the trend at higher VTAI. As expected, there is a conspicuous relation between VTAI and window orientation. Note however that, for the three locations in the Southern hemisphere (Nairobi, Wellington and Sydney), the sense of the North-South relation in the predictions is reversed. The North and South points for those locations in the Southern hemisphere are identified by an enclosing box.

The annual electrical energy predictions for lighting the office with EC glazing $\left(Q_{E C}\right)$ are also given in Figure 3. The North and South predictions for the Southern hemisphere locations are identified as above. As with the Basecase, the relation between orientation and VTAI is evident. But a new feature emerges: there is a clear relation between the lighting energy and the VTAI for any given orientation. This is most conspicuous for the North orientation and seems to be related to latitude.

\subsection{Energy Benefit for EC and FPV}

The energy benefit in switching from a Basecase to an EC setting was defined as the predicted saving in annual electric lighting energy, i.e.

$$
\text { Energy Benefit }=Q_{B}-Q_{E C}
$$

The energy benefit is plotted against VTAI in Figure 4a. The orientations are indicated as before. A least-squares regression line is drawn.

The energy benefit from PV is the delivered power from the PV array that can displace electric lighting usage. The PV energy benefit is also plotted in Figure 4a to allow direct comparison with the EC energy benefit. Recall that the energy benefit for both PV and EC is calculated on an annual basis per metre width of facade. As expected, the PV energy benefit shows a strong 
linear relation to the VTAI. The annual efficiency in terms of delivered power divided by the VTAI is approximately $14 \%$. Two dashed lines are shown to indicate the energy benefit from PV devices that deliver annual efficiencies of $20 \%$ and $25 \%$. These annual efficiencies are of course less than the usual stated efficiency which is determined under standard test conditions.

A key feature of this study is the direct comparison of these two technologies in terms of the predicted energy benefit. Most striking is the finding that, for the majority of facades with a VTAI less than $\sim 1000 \mathrm{kWh} / \mathrm{m}^{2}$, the energy saved by switching to EC glazing is predicted to be greater than the energy generated by facade PV.

Some of the lowest EC energy benefit values are associated with the highest VTAI. This is most likely to result from a high incidence of occasions when, even with the blinds lowered in the Basecase model, there is still sufficient provision of daylight (i.e. $\geq 500$ lux) so that the lights remain off.

\subsection{Deployment of ECs and FPVs across multiple fa- cades}

There is always the potential for dispute between the architect and the engineer because a design driven by aesthetic considerations alone rarely offers the best environmental solution. Modern buildings often have the same facade detailing all the way round, regardless of the prevailing orientation of each of the principal facades. In this section, the overall energy benefit that results from deploying ECs or facade PVs on an increasing number of facades (i.e. from one to four) is determined using a incremental additive approach. The four energy benefit predictions (i.e. facade orientations) for each location and facade type are sorted into descending rank order. For example, $Q_{1}, Q_{2}, Q_{3}, Q_{4}$, where $Q_{1}$ is the greatest and $Q_{4}$ the lowest. For either of the technologies, the maximum energy benefit (per metre) is achieved from de- 
ploying only on one facade, i.e. the highest of the four energy benefit values. This is shown in the column labelled " 1 of 4 " in Table 4 . The maximum energy benefit (per metre) across two facades is the mean of the two highest energy benefit predictions (column "2 of 4" in Table 4), and so on. Note that this applies strictly to an office building with a square plan and identical office spaces around the entire perimeter, Figure 1c. For other shapes of building it would be necessary to apply a weighting to the mean depending on the length of facade and its orientation.

As expected, for all locations the energy benefit per metre width of facade for PV drops markedly as the deployed number of facades is increased from one to two. The reduction in energy benefit in increasing the number of deployed facades from two to three is less dramatic because the irradiation on the East and West facades is usually the same. Increasing the number of deployed facades from three to four however results in another substantial drop in the mean energy benefit for FPVs as the least effective facade is now included in the calculation of the mean.

The mean energy benefit from EC glazing is greater than that for FPV for all cases. There were instances with the very highest VTAI $\left(>1000 \mathrm{kWh} / \mathrm{m}^{2}\right)$ where the energy benefit for facade PV exceeded the EC benefit for that particular orientation (Figure 4). However, it was always the case that the EC benefit on another facade always exceeded the highest facade PV benefit. Additionally, there is a much smaller difference in the EC energy benefit predictions across the four orientations for any one location. In fact, the data given in Table 4 suggests that EC glazing could be effective across all facade orientations for many locations. This clearly has benefits in terms of design and procurement if the same materials are used across all the facades. More importantly for reducing primary energy demand in buildings, ECs are predicted to be effective for most if not all facade orientations for the majority 
of climates. Recall also that the energy benefit from ECs (against standard practice) is likely to be greater, perhaps markedly so, than the values given in Table 4 because of the likely consistent under-prediction of lighting energy use for the Basecase.

\subsection{The prospects for higher efficiency photovoltaic modules}

Announcements of "record breaking" PV efficiencies are a regular occurrence in the technology pages of newspapers. A recent announcement put the record at $42.8 \%{ }^{(21)}$. These high efficiencies are significant demonstrations of new or refined formulations for PV devices. However, the efficiencies of prospective commercial PV modules in the near to medium term are much lower than the forty or so percent attainable in the laboratory. The module efficiency targets given in the PV2030 "road map" for Japan anticipate efficiencies for crystalline silicon PV of 16, 19 and $22 \%$ to be achieved by the years 2010, 2020 and 2030 respectively ${ }^{(22)}$. Cost of production is just as significant a factor as module efficiency and there is considerable research activity dedicated to the development of low cost formulations based on organic technology. The anticipated module efficiencies for these formulations in the PV2030 "road map" are 6, 10 and 15\% to be achieved in subsequent decades as indicated previously ${ }^{(22)}$. Notwithstanding any major breakthroughs in PV technology that can be carried through to large-scale commercial production, delivered efficiencies in the 20 to $25 \%$ range are not likely to be achieved for a decade or more. 


\section{Model veracity and prediction reliability}

The potential for making use of daylight to displace electrical lighting will depend strongly on the daylight threshold value at which some shading (e.g. blinds) or attenuation device (e.g. EC glazing) is applied. Daylight illuminances higher than typical design levels (e.g. 500 lux) need to be allowed at the front of the office to allow penetration of worthwhile daylight deeper into the space. A value of 2000 lux was used in the Basecase as the threshold value above which blinds would be lowered. The same value was used as the control set-point at the front of the office for the EC glazing model. As noted earlier, studies have revealed that illuminances exceeding approximately 2000 lux have generally caused occupants to activate shading devices (e.g. to lower blinds). Thus the lighting energy predictions given here are founded on what might be called a 'full' exploitation of daylight. Further studies need to be carried out to better delineate user preferences for, and tolerances to, higher than design level illuminances, since these data will be vital for the calibration of active systems that strive to maximise the exploitation of daylight without causing undue visual discomfort. Until such studies have been carried out, the 2000 lux values seems reasonable based on what has been reported in the literature to date.

\subsection{Basecase switching and blinds model}

It is acknowledged that the findings are dependant to a large degree on various assumptions regarding the operational aspects of each setting. This was especially so for the Basecase setting against which the energy benefit of EC glazing was determined. The Basecase predictions are the most likely to deviate from what could be expected under real conditions because they are the most dependant on human factors (i.e. occupant behaviour). How the Basecase results might differ from a plausible, real space is discussed in this 
section. Three key parameters (glazing type, blinds operation and lighting controls) and their assumed value or operation are listed in Table 3. In each case, a more realistic value or mode of operation is likely to result in greater energy consumption for electric lighting than that predicted.

A previous modelling study using the same control algorithm and multiple climate zones determined that clear glazing, in combination with daylight responsive blinds, resulted in lower annual electric lighting usage than tinted, solar control glazing ${ }^{(6)}$. The models for the operation of the blinds and the electric lighting assume an ideal, daylight responsive operation. It has been noted in several studies that actual operation differs markedly from this ideal. Once blinds are lowered, they will tend to stay in that position, often until the end of the day, regardless of the daylight levels ${ }^{(9)}$. Similarly, manually operated luminaires, once switched on, will tend to stay on regardless of the provision of daylight. Accordingly, actual operation of blinds and lights in real settings may well result in higher electric lighting usage for the Basecase than the forecast given in Figure 3. This is suggested in that figure by the hashed-line 'balloon' with upwards-pointing arrow that encompasses all the Basecase lighting energy prediction points.

The deterministic switching and shade models used here are of course much simpler and less realistic than behavioural models such as Lightswitch2002. That model employs probabilistic algorithms to mimic patterns of user switching and shade deployment/retraction. However, as noted in Reinhart's paper: "Even though the Lightswitch-2002 algorithm is based on scientifically sound methods, it is still of 'preliminary' nature as are the underlying behavioral patterns" ${ }^{(23)}$. In the example given in that paper - a daylit office with a southern facade located in Toronto (Canada) - the annual electric lighting energy demands for a manually controlled lighting and blind system was predicted to vary between 10 and $39 \mathrm{kWh} / \mathrm{m}^{2}$ for different user types. 
Assuming that the four different user types occur with equal frequency, the mean light demand was predicted to be $27.2 \mathrm{kWh} / \mathrm{m}^{2}$. Note that the glazing and office dimensions used for the study reported here were similar to those used by Reinhart. The range reported in lighting energy demand corresponds to 84 and $327 \mathrm{kWh} / \mathrm{m}$ using the per metre width of facade basis for annual lighting energy demand (i.e. for an office depth of $6 \mathrm{~m}$ ) and using a continuous seven day occupancy. Applying again the assumption regarding the four user types gives $163 \mathrm{kWh} / \mathrm{m}$. Note that the range in demand for the various behavioural types reported by Reinhart under just one climate (i.e. $243 \mathrm{kWh} / \mathrm{m}$ ) exceeds the range predicted in the Basecase model for all climates $(\approx 70 \mathrm{kWh} / \mathrm{m})$. A recent paper by Bourgeois et al compares predictions of behavioural types for two climates using a fixed orientation ${ }^{(24)}$. Given the degree of uncertainty regarding the frequency of occurrence of the four user types and the resulting large sensitivity in the predicted demand, a deterministic model was employed for this study of 56 climate-orientation combinations as a necessary simplification until the sensitivity of predictions to occupant models under varying climates has been more fully investigated.

\subsection{EC control model}

In contrast to the switching/blinds model used for the Basecase, a real office with EC glazing and daylight responsive lighting controls is likely to perform in a similar manner to that of the simulated EC office because the operation of the lights and the glazing is automatic. (Provided, of course, that the specification is similar and the automated systems are not interfered with.) Thus, the electric lighting energy forecasts for the EC office are likely to be reliable. The only significant difference between predicted performance and plausible reality is likely to result from those occasions in the year when there is naturally occurring short-timescale variation in the magnitude of the sun 
and sky illumination, i.e. bright, fast moving clouds. For these conditions, transient effects including the response of the EC glazing and lighting controls may figure in the overall assessment of the electric lighting usage. The likely magnitude of this effect is impossible to anticipate - it would probably require short-timestep modelling ( $\leq 1$ minute) which includes the dynamic response (i.e. switching time) of the EC glazing.

To recap, for a real office with blinds and on/off lights, the electric lighting usage is likely to be consistently higher than that forecast by the simulation, largely because of human factors. In contrast, the electric lighting usage predictions for the EC office are likely to be similar to those for a real implementation. This being so, it can be reasonably assumed that the predicted energy benefit in switching to EC glazing (shown in Figure 4a) is an underestimation, perhaps by a large margin, of what would be likely in reality. This is suggested in Figure 4a by the hashed-line 'balloon' with upwardspointing arrow that encompasses all the EC energy benefit prediction points. The delivered energy from an actual facade PV of similar specification to that modelled is unlikely to deviate from that shown in Figure 4a.

\subsection{Other factors for the EC setting: visual comfort and cooling load}

It is acknowledged that visual comfort is difficult to quantify. This is especially so under dynamic daylight conditions where large variations in both the quantity and distribution of illumination and perceived luminance are typical. It is possible however to estimate the occurrence of illumination conditions that are likely to be associated with discomfort. As noted, a survey of published studies on occupant behaviour under daylight conditions revealed that illuminances significantly higher than 500 lux are commonly tolerated up to a maximum of about 2000 lux. Illuminances greater than 2000 lux of- 
ten precipitated the lowering of blinds or shading devices by the occupants. The "useful daylight illuminance" scheme was formulated with 2000 lux as the upper limit for daylight illuminances that are considered either welcome or tolerable by occupants ${ }^{(6)}$. Illuminances greater than this upper limit were noted in many occupant studies to be associated with discomfort ${ }^{(25)(26)(27)}$.

Thus, comfort for the EC setting is evaluated in terms the percentage of the working year for which useful daylight illuminance is exceeded. In other words, it gives an indication of the ability of the EC glazing to prevent the maximum work plane illuminance from exceeding 2000 lux. These exceedance values are plotted against VTAI in Figure 4b. The plot is shown directly below that in Figure 4a so that comparison can be made with the corresponding energy benefit values. It is possible that those cases with low occurrence of UDI exceedance (less than $5 \%$ or perhaps $10 \%$ ) could be tolerated by occupants throughout the year. Cases with a significant UDI exceedance may require additional shading (e.g. blinds) to supplement that offered by the EC glazing at minimum transmission. The addition of supplementary shading may severely impair the overall performance of ECs. This will almost certainly be the case if the additional shading is manually operated blinds which have a high probability of being left closed when no longer needed. Whether manual or automatic, the need for additional shading to attenuate high daylight illuminances will lessen the appeal of EC glazing since this would add to both cost and complexity. Thus ECs would be a more effective, and therefore preferred, glazing option where they could offer a single technology solution for both the modulation of useful daylight and the prevention of excessive daylight levels.

It is likely that EC glazing will also reduce the cooling load for many of the cases studied ${ }^{(5)}$. In which case, the energy benefit is, once again, likely to be greater than that shown in Figure 4a. It may well that be that 
the additional energy benefit due to savings in cooling load will be greatest for those cases with the highest VTAI. And so the EC energy benefit could begin to rival that from facade PV for these cases. However, these are also the cases where EC glazing would probably require additional shading. Ideally, the evaluation should be repeated using a coupled dynamic thermal model to quantify the energy benefit of reduced cooling loads.

\section{Conclusion}

This paper has presented a methodology to make quantitative comparison of the energy benefit from two very different advanced facade technologies - ECs which are energy saving over the horizontal area of the office space and PVs which are energy generating over vertical sections of opaque facade. A key feature of the study was the relation of the energy benefit to the predicted vertical total annual irradiation for all 56 combinations of fourteen climate and four orientations. The VTAI can be considered to be a quantification of the "local solar micro-climate".

The findings have shown that the predicted energy benefit from replacing standard blinds (and on/off switching) with EC glazing (and daylight responsive dimming) can be greater than the energy benefit from facade PV for the majority of cases. Furthermore, those cases with low to moderate values for experienced vertical total annual irradiation appear to be the best candidates for EC glazing because of the high energy benefit and their ability to temper the luminous environment without recourse for additional shading. Thus, although ECs perform well for all climates and orientations, they may in fact be better suited to the less sunny climates. This finding is perhaps counter to the commonly accepted role for EC glazing as a solar control device for warm, sunny climates. However it is acknowledged that these findings need to be further tested using more realistic behavioural models for light switching and 
the use of blinds.

Disregarding the issue of occasional high illuminances - a minimum transmission lower than 0.1 would be needed to reduce the occurrences of high illuminances - ECs provide a significantly greater energy benefit than facade PVs when each are deployed across multiple facades. ECs may therefore have a significantly greater potential overall to save energy in buildings than facade PVs because they can be deployed effectively over more facades.

$\mathrm{PV}$ is established as a technology that is widely perceived as capable of 'harvesting' solar energy. For non-domestic buildings, there are limits to the effective deployment of PV. The roof is often the ideal place as it is easy to site the panels with the optimum tilt and orientation. The roof area however is usually small in comparison to the vertical facade area for high rise office buildings. Facade PV is a viable option for those facade orientations that experience high levels of irradiation. That usually limits the deployment to just one facade, possibly two or three if the combination of module cost and climate allows. Small increases in PV efficiency are expected through improved formulations. However it is unlikely that greater FPV output would be considered at the expense of an increased floor pitch (i.e. a larger opaque area for deployment) as the additional construction costs would be prohibitive. All these factors place limits on the area of building facade that can be considered suitable candidates for the effective deployment of PVs, and therefore limits also on the potential for large-scale 'harvesting' of solar energy.

In contrast, 'harvesting' of daylight by EC glazing is predicted to be a viable prospect for perhaps all building facades and for many climates around the world. There may be additional benefits to occupants in offices with EC glazing in terms of the provision of a well-tempered daylit environment. Shading, which is unavoidable in dense urban environments and 
greatly reduces PV efficiency, may not have such a detrimental impact on EC performance since the EC benefit was greatest for the lower values of VTAI.

EC glazing is still in the development and proving phase, but commercial production is expected in the near future and viability will depend on meeting cost and durability criteria. It is hoped that these will be achieved because the findings described in this paper lend credence to Selkowitz's statement that the dynamic control of daylight is indeed the "Holy Grail of the fenestration industry". Further, it is our hope that a viable and cost-effective EC formulation proves to be less elusive than the Grail.

\section{Acknowledgements}

This work was carried out in support of the activities of IEA Task 31. The comments and suggestions of both referees are gratefully acknowledged. 


\section{Captions}

Table 1 Climate datasets: City, country and location

Table 2 Summary of the evaluation settings

Table 3 Basecase office - forecast and likely reality

Table 4 Mean energy benefit across facades (progressing from highest to lowest)

Figure 1 Building model and design variants

Figure 2 Schematic of DC-based scheme

Figure 3 Electric lighting energy use for Basecase and EC glazing

Figure 4 Energy benefit and discomfort indicator 


\section{References}

[1] IEA. Photovoltaic power systems programme-strategy document 1998-2002,. Technical report, International Energy Agency, 1998.

[2] DTI. Photovoltaics in Buildings: BIPV Projects Programme - Strategy Document 1998-2002. Technical report, Dept. of Trade and Industry, 2000.

[3] V. Crisp, P. Littlefair, I. Cooper, and G. T. McKennan. Daylighting as a passive solar energy option: An assessment of its potential in nondomestic buildings. Building Research Establishment Report, Garston, CRC, 1988.

[4] S. Selkowitz and E.S. Lee. Advanced fenestration systems for improved daylight performance. Daylighting '98 Conference Proceedings Ottawa, Ontario, Canada, 1998.

[5] E. S. Lee and D. L. DiBartolomeo. Application issues for large-area electrochromic windows in commercial buildings. Solar Energy Materials and Solar Cells, 71(4):465-491, 2002.

[6] A. Nabil and J. Mardaljevic. Useful daylight illuminace: A new paradigm for assessing daylight in buildings. Lighting Research and Technology, 37(1):41-59, 2005.

[7] Eero Vartiainen. Electricity benefits of daylighting and photovoltaics for various solar facade layouts in office buildings. Energy and Buildings, 33(2):113-120, 2001.

[8] J. Mardaljevic. Daylight Simulation: Validation, Sky Models and Daylight Coefficients. PhD thesis, De Montfort University, Leicester, UK, 2000. 
[9] Michelle Foster and Tadj Oreszczyn. Occupant control of passive systems: the use of venetian blinds. Building and Environment, 36(2):149$155,2001$.

[10] A. Nabil. Performance Modelling for Advanced Envelope Systems. PhD thesis, De Montfort University Leicester, 2002.

[11] CIBSE. Understanding Building Integrated Photovoltaics TM 25. Chartered Institution of Building Services Engineers, London, 2000.

[12] J. A. Duffie and W. A. Beckman. Solar Engineering of Thermal Processes. John Wiley and Sons, Inc., 1991.

[13] BP. BP Solar, Products and Services, Solar Products. BP 585 Data Sheet.

[14] R. Sullivan, M. Rubin, and S. Selkowitz. Energy performance analysis of prototype electrochromic windows, Report number: LBL-39905 BS-360. Technical report, Lawrence Berkeley Laboratory, 1996.

[15] R. Sullivan, E. S. Lee, K. Papamichael, M. Rubin, and S. Selkowitz. Effect of switching control strategies on the energy performance of electrochromic windows, Report number: LBL-35453 BS-324. Technical report, Lawrence Berkeley Laboratory, 1994.

[16] R. Sullivan, E. S. Lee, M. Rubin, and S. Selkowitz. The energy performance of electrochromic windows in heating-dominated geographic locations, Report number: LBL-38252 BS-354. Technical report, Lawrence Berkeley Laboratory, 1996.

[17] S. Selkowitz, M. Rubin, E. Lee, and R. Sullivan. A review of electrochromic window performance factors, Report number: LBL-35486 OM-328. Technical report, Lawrence Berkeley Laboratory, 1994. 
[18] E.S. Lee, D. DiBartolomeo, and S. Selkowitz. Electrochromic windows for commercial buildings - Monitored results for a full-scale testbed, Report Number: LBNL-45415 DA-414. Technical report, Lawrence Berkeley National Laboratory, 2000.

[19] D. L. DiBartolomeo, E. S. Lee, F. M. Rubenstein, and S. Selkowitz. Developing a dynamic envelope/lighting control system with field measurements. Journal of the Illuminating Engineering Society, 26(1), 1996.

[20] S. Papaefthimiou, G. Leftheriotis, P. Yianoulis, T. J. Hyde, P. C. Eames, Y. Fang, P. Y. Pennarun, and P. Jannasch. Development of electrochromic evacuated advanced glazing. Energy and Buildings, 38(12):1455-1467, 2006.

[21] J. Schuman. A Pentagon Advance For Solar Energy. Wall Street Journal Online, 3 August 2007.

[22] M. Yamaguchi, Y. Ohshita, K. Arafune, H. Sai, and M. Tachibana. Present status and future of crystalline silicon solar cells in japan. Solar Energy, 80(1):104-110, 2006.

[23] Christoph F. Reinhart. Lightswitch-2002: a model for manual and automated control of electric lighting and blinds. Solar Energy, 77(1):15-28, 2004.

[24] D. Bourgeois, C. F. Reinhart, and I. Macdonald. Adding advanced behavioural models in whole building energy simulation: A study on the total energy impact of manual and automated lighting control. Energy and Buildings, 38(7):814-823, 2006.

[25] E. Vine, E. S. Lee, R. Clear, D. DiBartolomeo, and S. Selkowitz. Office workers response to an automated venetian blind and electric lighting system - a pilot study. Energy and Buildings, 28(2), 1998. 
[26] L. Roache. Summertime performance of an automated lighting and blinds control system. Lighting Research and Technology, 34(1), 2002.

[27] N Morel and D Lindelof. Bayesian optimization of user visual comfort. Lux Europa Proceedings, 2005. 


\begin{tabular}{lrr}
\hline City, Country & Latitude [degrees] & Longitude [degrees] \\
\hline Almeria, Spain & 36.83 & 2.45 \\
\hline Boulder, USA & 40.02 & 105.25 \\
\hline Cairo, Egypt & 30.05 & -31.25 \\
\hline Frankfurt, Germany & 50.03 & -8.55 \\
\hline Glasgow, UK & 55.87 & 4.43 \\
\hline Hong Kong, China & 22.30 & -112.40 \\
\hline Kew, UK & 51.47 & 0.28 \\
\hline Miami, USA & 25.80 & 80.27 \\
\hline Nairobi, Kenya & -1.28 & -36.82 \\
\hline Seattle, USA & 47.45 & 122.30 \\
\hline Singapore, Singapore & 1.30 & -103.80 \\
\hline St.Petersburg, Russia & 59.92 & -30.25 \\
\hline Sydney, Australia & -33.90 & -151.20 \\
\hline Wellington, New Zealand & -41.30 & -174.78 \\
\hline
\end{tabular}

Table 1: Climate datasets: City, country and location 


\begin{tabular}{lllll}
\hline Setting & $\begin{array}{l}\text { Blinds/EC } \\
\text { operation }\end{array}$ & $\begin{array}{l}\text { Electric } \\
\text { lighting }\end{array}$ & $\begin{array}{l}\text { Electric } \\
\text { energy use }\end{array}$ & $\begin{array}{l}\text { Energy } \\
\text { benefit }\end{array}$ \\
\hline Basecase & $\begin{array}{l}\text { Lower when } \\
\text { E }>2000 \text { lux }\end{array}$ & $\begin{array}{l}\text { On/off } \\
\text { to 500 lux }\end{array}$ & $Q_{B}$ & - \\
\hline EC & $\begin{array}{l}\text { Maintain } \\
\text { Dimming }\end{array}$ & $\begin{array}{l}\text { Dime } \\
\text { to 500 lux }\end{array}$ & $Q_{B}-Q_{E C}$ \\
& 2000 lux & to 5 & \\
\hline FPV & - & - & - & $Q_{F P V}$ \\
\hline
\end{tabular}

Table 2: Summary of the evaluation settings 


\begin{tabular}{|c|c|c|c|c|}
\hline Parameter & $\begin{array}{l}\text { Type/ } \\
\text { model }\end{array}$ & $\begin{array}{l}\text { Reality } \\
\text { congruence }\end{array}$ & $\begin{array}{l}\text { Effect on } \\
\text { prediction }\end{array}$ & $\begin{array}{l}\text { Energy } \\
\text { forecast }\end{array}$ \\
\hline $\begin{array}{l}\text { Standard } \\
\text { glazing }\end{array}$ & Clear & $\begin{array}{l}\text { Sunnier climates } \\
\text { likely to have } \\
\text { tinted glazing }\end{array}$ & $\begin{array}{l}\text { Lighting energy } \\
\text { likely to be } \\
\text { higher for } \\
\text { tinted glazings }\end{array}$ & $\begin{array}{l}\text { Under } \\
\text { predicted }\end{array}$ \\
\hline $\begin{array}{l}\text { Blinds } \\
\text { operation }\end{array}$ & $\begin{array}{l}\text { Ideal, } \\
\text { daylight } \\
\text { linked }\end{array}$ & $\begin{array}{l}\text { Blinds likely to stay } \\
\text { lowered rather than } \\
\text { raised in response to } \\
\text { reduced illuminance }\end{array}$ & $\begin{array}{l}\text { Electric lights } \\
\text { likely to be on } \\
\text { more often } \\
\text { than predicted }\end{array}$ & $\begin{array}{l}\text { Under } \\
\text { predicted }\end{array}$ \\
\hline $\begin{array}{l}\text { Lighting } \\
\text { controls }\end{array}$ & $\begin{array}{l}\text { Ideal, } \\
\text { daylight } \\
\text { linked }\end{array}$ & $\begin{array}{l}\text { Lights likely to } \\
\text { remain on even } \\
\text { even when there } \\
\text { is sufficient daylight }\end{array}$ & $\begin{array}{l}\text { Electric lights } \\
\text { likely to be on } \\
\text { more often } \\
\text { than predicted }\end{array}$ & $\begin{array}{l}\text { Under } \\
\text { predicted }\end{array}$ \\
\hline
\end{tabular}

Table 3: Basecase office - forecast and likely reality 


\begin{tabular}{llrrrr}
\hline & \multicolumn{5}{c}{ Mean energy benefit per unit } \\
Location & Type & \multicolumn{3}{c}{ length of facade $[\mathrm{kWh} / \mathrm{m}]$} \\
& & 1 of $4^{2}$ & 2 of 4 & 3 of 4 & 4 of 4 \\
\hline Almeria, & EC & 182 & 173 & 158 & 149 \\
Spain & PV & 155 & 134 & 126 & 100 \\
\hline Boulder, & EC & 176 & 173 & 156 & 146 \\
USA & PV & 169 & 144 & 129 & 102 \\
\hline Cairo, & EC & 181 & 174 & 158 & 147 \\
Egypt & PV & 133 & 119 & 114 & 92 \\
\hline Frankfurt, & EC & 164 & 158 & 150 & 144 \\
Germany & PV & 89 & 77 & 73 & 60 \\
\hline Glasgow, & EC & 144 & 144 & 135 & 131 \\
UK & PV & 93 & 80 & 70 & 57 \\
\hline Hong Kong, & EC & 178 & 172 & 164 & 157 \\
China & PV & 81 & 80 & 72 & 61 \\
\hline Kew, & EC & 157 & 152 & 144 & 137 \\
UK & PV & 96 & 81 & 75 & 61 \\
\hline Miami, & EC & 183 & 172 & 160 & 153 \\
USA & PV & 124 & 114 & 109 & 90 \\
\hline Nairobi, & EC & 170 & 169 & 163 & 160 \\
Kenya & PV & 101 & 96 & 89 & 82 \\
\hline Seattle, & EC & 168 & 165 & 154 & 147 \\
USA & PV & 109 & 95 & 85 & 69 \\
\hline Singapore, & EC & 165 & 164 & 162 & 157 \\
Singapore & PV & 106 & 82 & 74 & 69 \\
\hline St.Petersburg, & EC & 136 & 131 & 125 & 118 \\
Russia & PV & 111 & 96 & 80 & 64 \\
\hline Sydney, & EC & 173 & 172 & 156 & 145 \\
Australia & PV & 136 & 115 & 107 & 86 \\
\hline Wellington, & EC & 175 & 164 & 156 & 147 \\
New Zealand & PV & 124 & 109 & 97 & 78 \\
\hline & & & & & \\
\hline
\end{tabular}

Table 4: Mean energy benefit across facades (progressing from highest to lowest) 

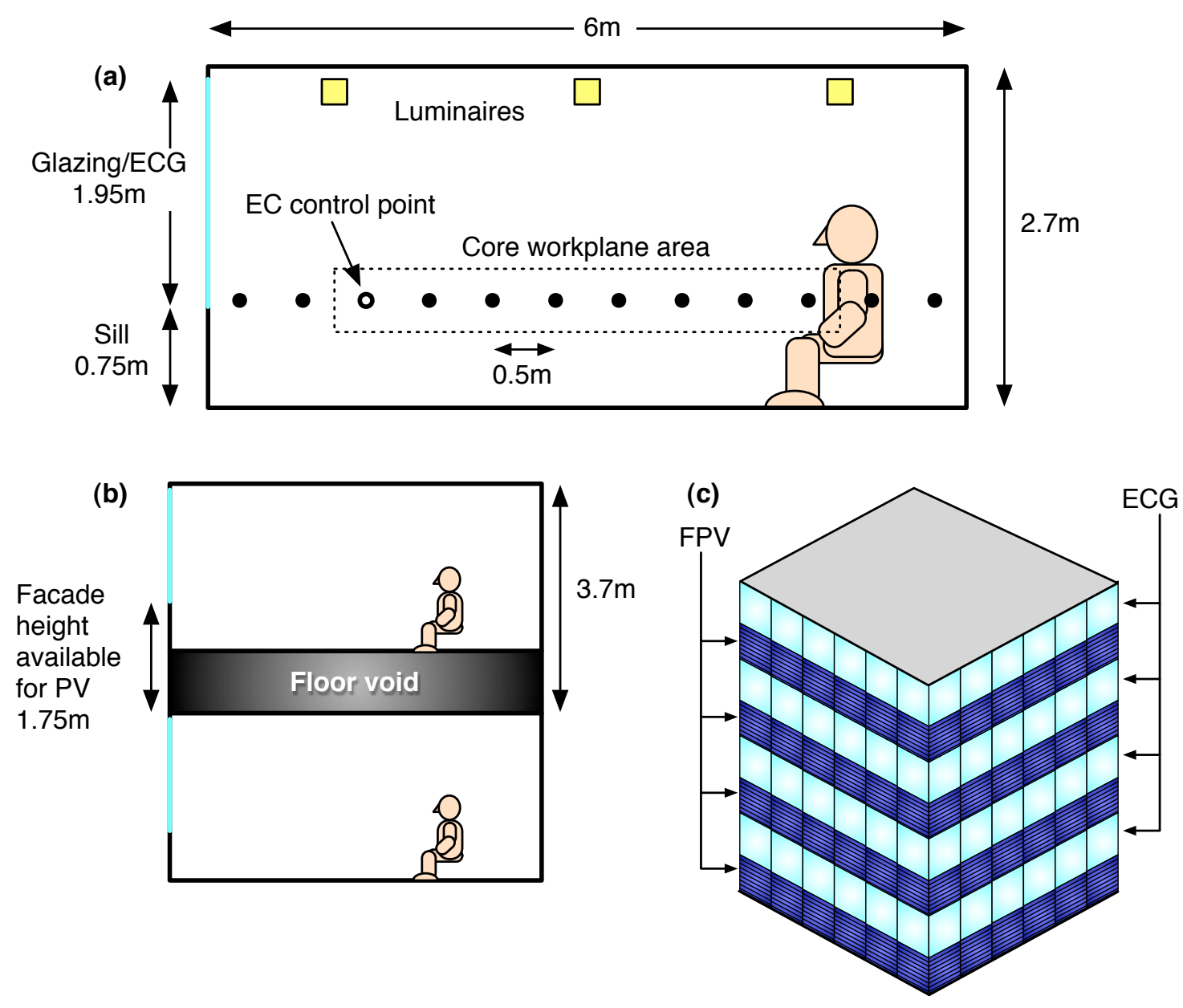

Figure 1: Building model and design variants 


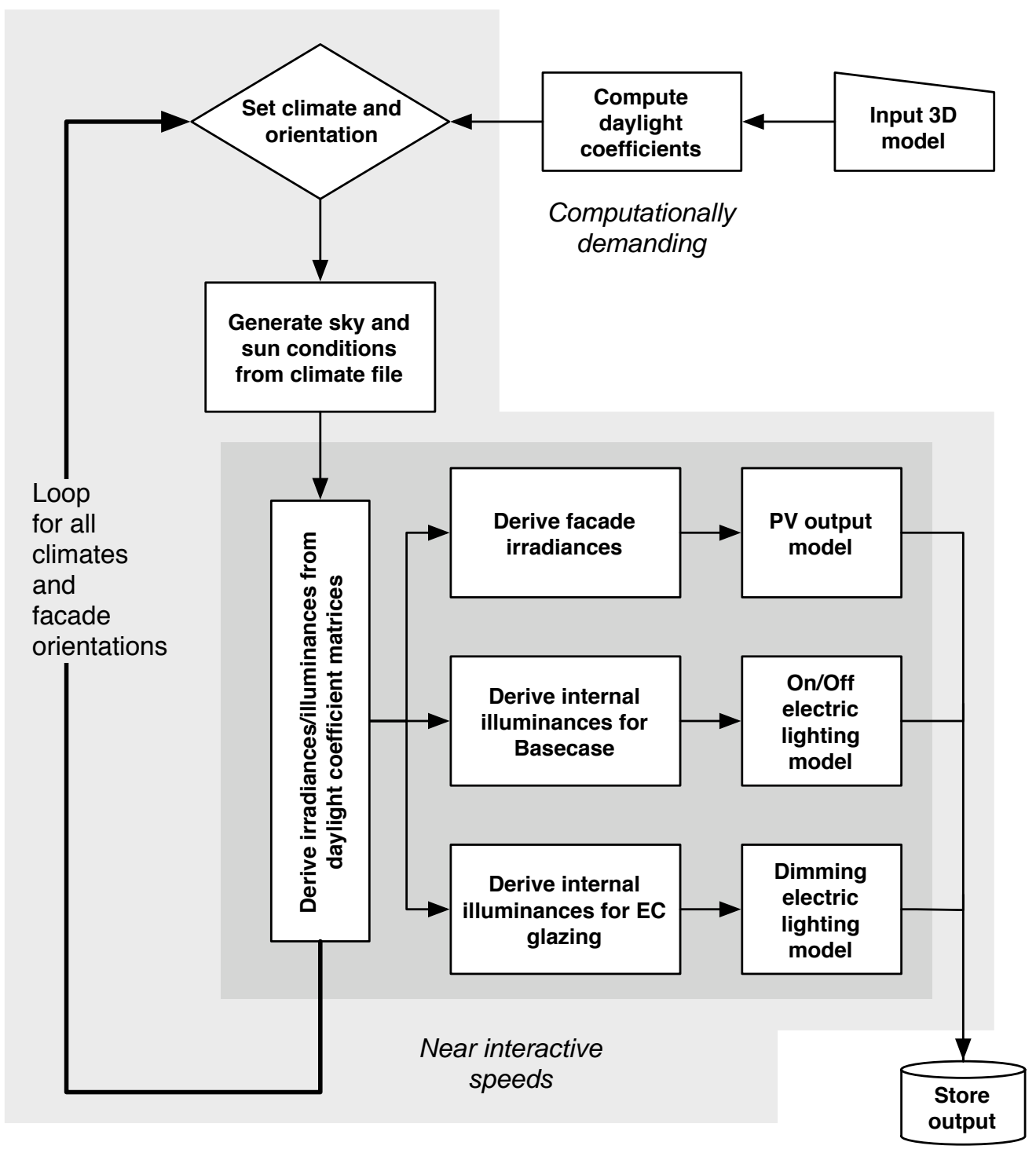

Figure 2: Schematic of DC-based scheme 
Lighting Energy Use: Basecase and EC Glazing

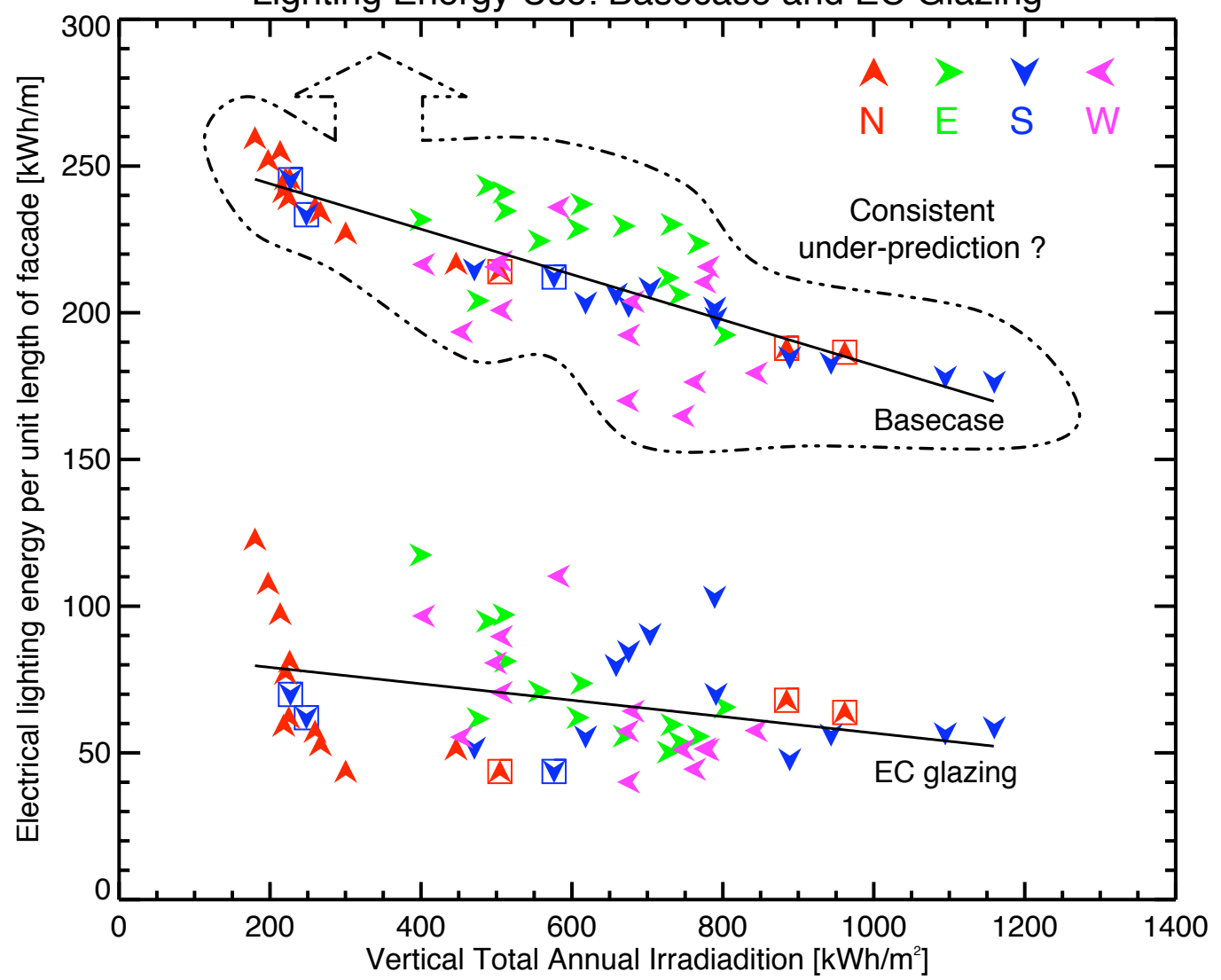

Figure 3: Electric lighting energy use for Basecase and EC glazing 

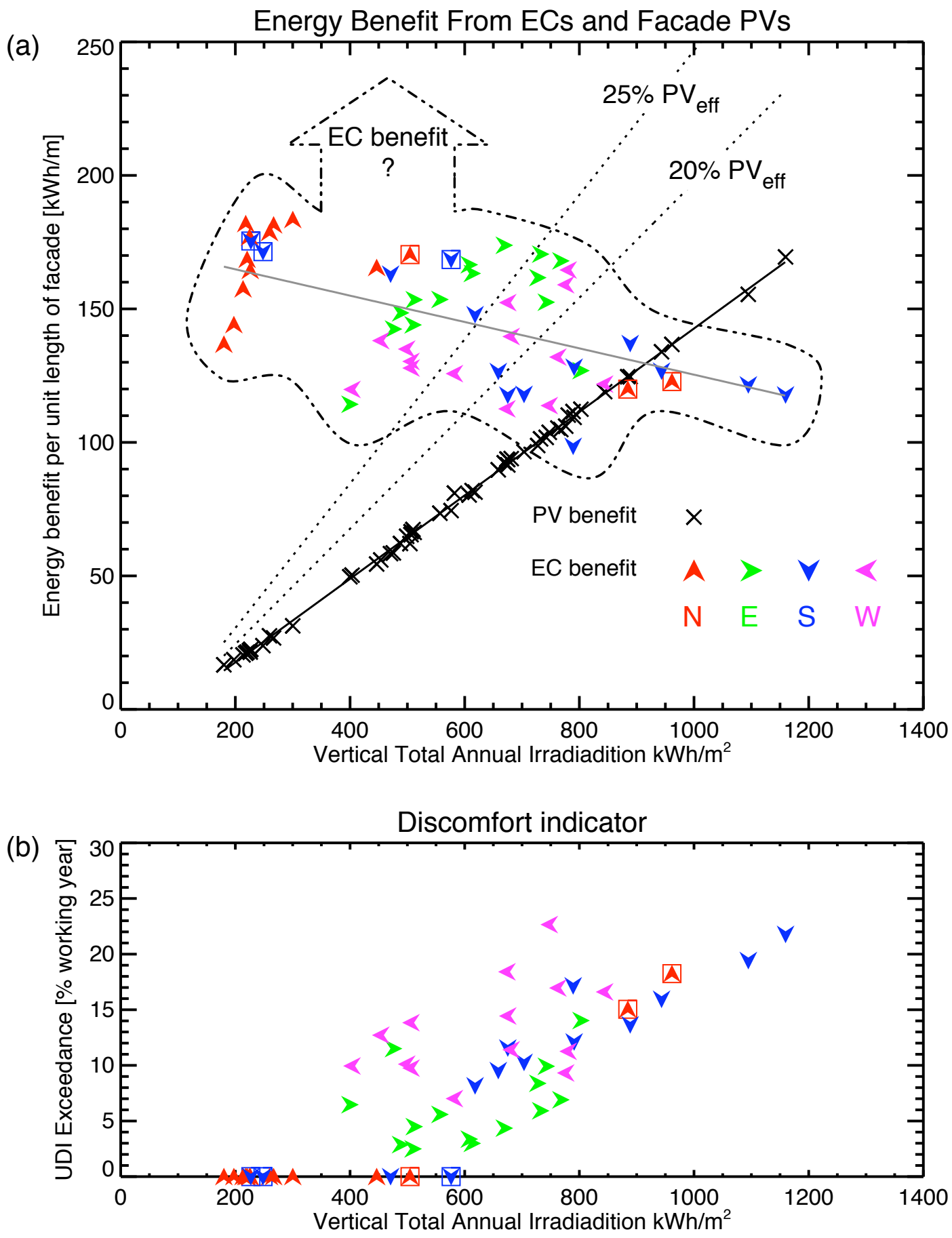

Figure 4: Energy benefit and discomfort indicator 